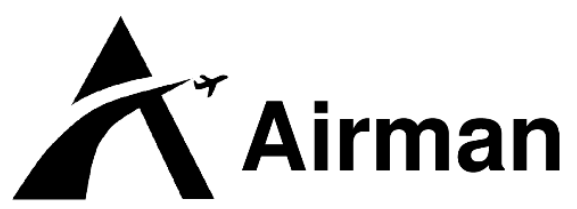

Jurnal Teknik dan Keselamatan Transportasi

\title{
Rancang Bangun Sistem Monitoring Fasa dan Daya berbasis Internet of Things (IoT) menggunakan Smartphone
}

\section{Design of Monitoring System Fasa and Power-based Internet of Things using Smartphone}

\author{
Laras Indah Sucita ${ }^{1}$, Yayuk Suprihartini ${ }^{2}$ \\ 23417056@ppicurug.ac.id ${ }^{1}$, yayuk.suprihartini@ppicurug.ac.id ${ }^{2}$ \\ Politeknik Penerbangan Indonesia Curug
}

\begin{abstract}
ABSTRAK
Sistem distribusi merupakan salah satu sistem tenaga listrik yang mempunyai peran penting karena berhubungan langsung dengan pemakai energi listrik. Ketidak seimbangan beban dan kegagalan salah satu fasa sering kali terjadi pada sistem distribusi tiga fasa. Alat ukur penelitian dibutuhkan dalam memonitor secara online untuk mengetahui nilai real time dari sebuah sistem distribusi. Dalam penelitian ini akan dirancang sebuah alat monitoring fasa dan daya berbasis Internet of Things dalam sistem distribusi tiga fasa, yang menggunakan media internet dengan perangkat smartphone sehingga bisa diakses secara jarak jauh menggunakan perangkat Arduino Mega dan perangkat Wemos D1 Mini dengan sensor PZEM-004T. Sehingga tampilan dari hasil monitoring dapat diakses melalui perangkat smartphone menggunakan aplikasi Blynk.
\end{abstract}

Kata kunci: Tiga Fasa; Blynk; Monitoring; Internet of Things

\section{ABSTRACT}

A distribution system is one of the systems in electrical power that has an important role because it is directly connected with users. Usually, there are often unbalanced loads and phase failures on the three-phase distribution system. Measuring tools here are needed in online monitoring to find out the real-time value of a distribution system. Phase and power monitoring tool will be designed in a three-phase distribution system that uses the internet so that it can be accessed remotely and uses Arduino Mega, Wemos D1 Mini device with PZEM-004T sensor. So that the display of monitoring results can be accessed via smartphone device using the Blynk application

Keyword: Three Phase; Blynk; Monitoring; Internet of Things 


\section{PENDAHULUAN}

Di indonesia untuk memenuhi kebutuhan dalam suplai listrik, sistem 1 fasa dikembangkan menjadi tiga fasa. Sistem ini menggunakan tiga gelombang sinusoidal yang mempunyai sudut fasa masing-masing 120 derajat. Sistem tiga fasa umumnya diterapkan pada jaringan listrik yang disuplai oleh PLN mulai dari pembangkit sampai dengan jarigan tegangan rendah. Pelanggan listrik perumahan dengan daya dibawah 3500VA menerima aliran listrik satu fasa dengan menggunakan dua kabel penghantar yaitu kabel fasa dan netral. Sedangkan pelanggan listrik dengan daya diatas 3500VA akan menerima aliran listrik tiga fasa dengan menggunakan empat kabel penghantar. Instalasi listrik tiga fasa menyediakan daya yang lebih besar dan pada umumnya digunakan pada industri dan pabrik untuk menggerakkan motor mesin yang memerlukan daya besar. Dengan besar beban atau daya yang sama, maka semakin besar tegangan listrik akan semakin kecil arus yang dihasilkan, dan semakin kecil arus yang mengalir tentunya akan semakin kecil diameter penampang penghantar yang dibutuhkan.

Pada kondisi saat ini teknisi hanya mengatahui ada salah satu fasa yang hilang dalam sistem tiga fasa, akan tetapi tidak megetahui fasa manakah yang hilang apakah itu fasa $\mathrm{R}, \mathrm{S}$ atau $\mathrm{T}$.

Alat monitoring kegagalan salah satu fasa pada kabel R, S, T atau sistem tiga fasa dan alat monitoring daya dapat digunakan sebagai pengaman yang bekerja untuk memproteksi fasa supaya selalu dalam monitoring (Amaro N., 2017). Hilangnya salah satu fasa akan menimbulkan tegangan yang tidak simetris dan dapat merusak peralatan yang memakai sistem tiga fasa. Sehingga apabila terjadi gangguan terhadap sistem, maka alat ini akan memonitoring fasa dan mengirimkan notifikasi kepada pengguna melalui smartphone android dan kegagalan pada fasa tesebut dapat segera diperbaiki oleh teknisi.

Identifikasi masalah pada penelitian ini adalah sebagai berikut:

1. Apakah teknisi mengetahui apabila terjadi hilangnya salah satu fasa listrik?

2. Bagaimana cara supaya teknisi dapat monitoring kegagalan fasa dan daya listrik?

\section{Landasan Teori}

\section{Sistem 3 Fasa}

Pembangkitan dan transmisi tenaga listrik akan lebih efisien bila menggunakan sistem fasa jamak (polyphase) yang menggunakan dua, tiga atau lebih tegangan sinusoida. Ketidakseimbangan tegangan adalah terjadinya variasi tegangan dalam sistem tenaga listrik dimana besaran tagangan antar fasa tidak sama akibat adanya perbedaan sudut fasa $\mathrm{R}, \mathrm{S}$, dan $\mathrm{T}$. Tegangan antar fasa tidak bisa $100 \%$ seimbang, namun ketika rasio ketidakseimbangan tegangan menjadi berlebihan dapat menciptakan masalah.

\section{Catu Daya Linier}

Perangkat elektronika mestinya dicatu oleh suplai arus searah DC yang stabil supaya dapat bekerja dengan baik. Baterai atau accu adalah sumber catu daya DC yang paling baik. Namun untuk aplikasi yang membutuhkan catu daya lebih besar, sumber dari baterai tidak cukup. Sumber catu daya yang besar adalah sumber bolak-balik AC dari pembangkit tenaga listrik. Untuk itu diperlukan suatu perangkat catu daya yang dapat mengubah arus AC menjadi DC.

\section{Rectifier}


Pada dasarnya konsep penyearah dibagi menjadi 2 jenis, yaitu penyearah setengah gelombang dan penyearah gelombang penuh. Prinsip kerja penyearah adalah bahwa pada saat sinyal input berupa siklus positif maka dioda akan mendapatkan forward bias sehingga arus mengalir ke beban, dan sebaliknya jika sinyal input berupa siklus negatif maka menjadi reverse bias sehingga arus tidak mengalir.

Transformator diperlukan untuk menurunkan tegangan AC dari jala-jala listrik pada kumparan primernya menjadi tegangan AC yang lebih kecil pada kumparan sekundernya.

\section{Tegangan listrik}

Tegangan listrik adalah besarnya beda energi potensial antara dua buah titik yang diukur dalam satuan volt (V). Tegangan dapat juga diartikan sebagai joule per coulomb. Tegangan didefinisikan sebagai kerja yang diperukan untuk memindahkan satu unit muatan dari satu terminal ke terminal yang lain

\section{Arus Listrik}

Listrik ada karena adanya muatan listrik, pergerakan muatan menimbulkan arus listrik. Coulomb adalah satuan yang menyatakan muatan. Tujuan dari sebuah rangkaian listrik adalah memindahkan muatan sepanjang lintasan yang diinginkan. Definisi arus itu sendiri adalah laju perubahan muatan persatuan waktu yang diukur dalam satuan ampere (A).

\section{Daya Listrik}

Laju energi yang diserap ataupun yang dikirim disebut daya, sedangkan daya listrik adalah banyaknya energi listrik yang mengalir setiap detik atau joule per second yang diukur dalam satuan watt $(\mathrm{W})$.

\section{Sensor PZEM-004T}

Sensor PZEM-004T adalah sebuah sensor yang dapat mengukur tegangan, arus, power dan energi dari arus AC. Sensor ini mengeluarkan output dengan komunkasi serial. Modul PZEM-004T sudah dilengkapi dengan sensor tegangan dan sensor arus (CT) yang sudah terintegrasi. PZEM-004T adalah sebuah hardware yang berfungsi untuk mengukur parameter dari tegangan, arus dan daya.

\section{Wemos D1 Mini}

Wemos D1 Mini adalah salah satu produk mini IoT board berbasis mikrokontroller ESP8266 ESP-12 buatan perusahaan China, WEMOS. Produk ini merupakan miniatur dari Wemos D1 yang desainnya mirip arduino uno. Mungkin bisa dikatakan Wemos D1 mini adalah versi arduino nanonya wemos D1. Pada board Wemos D1 Mini ini dapat langsung diprogram ESP-12 tanpa bantuan board proggrammer/ usb TTL esternal karena Wemos D1 Mini dilengkapi dengan chip $\mathrm{CH} 340$ sebagai converter ust to serial internal. Inilah salah satu keunggulan Wemos D1 Mini ketimbang menggunakan board ESP-12 biasa (bare board) yakni akan lebih dimudahkan saat proggramming dan debugging D1 Mini memiliki converter usb serial terintegrasi dengan switch programming dan running mode pada ESP-12.

\section{LCD}

LCD (Liquid Crystal Display) atau display elektronik adalah salah satu komponen 
elektronika yang berfungsi sebagai tampilan suatu data, baik karakter, huruf ataupun grafik. LCD (Liquid Cristal Display) adalah salah satu jenis display elektronik yang dibuat dengan teknologi CMOS logic yang bekerja dengan tidak menghasilkan cahaya tetapi memantulkan cahaya yang ada di sekelilingnya terhadap front-lit atau mentransmisikan cahaya dari back-lit.

\section{Buzzer}

Buzzer merupakan sebuah komponen elektronika yang masuk dalam keluarga transduser, yang dimana dapat mengubah sinyal listrik menjadi getaran suara. Nama lain dari komponen ini disebut dengan beeper

\section{Blynk}

Blynk adalah sebuah platform aplikasi yang bisa diunduh secara gratis untuk iOS dan android yang berfungsi untuk mengontrol module Wemos D1, arduino, Rapsberry Pi dan sejenisnya melalui internet. Blynk dirancang untuk perangkat Internet of Things dengan tujuan agar dapat mengontrol hardware dari jarak jauh, dapat menampilkan data, sensor, dapat menyimpan data, visual dan banyak hal canggih lainnya.

\section{Metode}

Penelitian yang dilakukan oleh penulis dalam pengumpulan data tersebut sebagai berikut:

1. Studi Literature

Studi literature dilakukan dengan mencari referensi teori yang relefan dengan kasus atau permasalahan yang ditemukan dan menelusuri sumbersumber tulisan yang pernah dibuat sebelumnya.

2. Metode Eksperiment
Eksperimen dilakukan pada perancangan blok-blok rangkaian dan software untuk menghasilkan alat sebagaimana tujuan awal. Dengan melakukan eksperimen terhadap perancangan dan pembuatan alat ini, diharapkan akan didapatkan rangkaian serta program sesuai dengan fungsi serta tujuan dari penelitian ini.

\section{Metode Wawancara}

Metode ini dilakukan dengan cara melakukan tanya jawab dengan beberapa narasumber secara langsung ditempat penelitian berlangsung, yaitu teknisi listriknya. Metode ini dilakukan supaya data yang di dapatkan lebih detail serta memperkuat data sebelumnya saat melakukan observasi lapangan.

\section{METODE PENELITIAN}

Pada saat ini teknisi hanya mengatahui ada salah satu fasa yang hilang dalam sistem tiga fasa, akan tetapi tidak megetahui fasa manakah yang hilang apakah itu fasa $\mathrm{R}, \mathrm{S}$ atau $\mathrm{T}$.

Dengan adanya alat ini diharapkan teknisi dapat lebih mudah dan cepat mengetahui kegagalan fasa atau mengetahui salah satu fasa yang hilang melalui media smartphone dan kemudian dapat segera melakukan perbaikan sehingga dapat menghindari kerusakan yang lebih besar pada peralatan listrik yang menggunakan beban tiga fasa. Dengan alat ini diharapkan juga agar teknisi dapat lebih mudah untuk memonitoring tegangan dan daya serta arus yang terpakai pada panel distribusi.

\section{Pembahasan}

Mengacu pada studi literature dilakukan dengan mencari referensi teori yang relefan dengan kasus atau permasalahan yang 
ditemukan dan menelusuri sumber-sumber tulisan yang pernah dibuat sebelumnya antara lain pada penulis Efrizal. F (2016), Fatoni N. H., Sabar S., Moh M. (2017) dan Daffa Rosydi, A., Prasetyono, E., \& Windarko, N. A. (2019).

\section{Sistem Perancangan}

Cara kerja alat ini di mulai dari pembacaan sensor tegangan dan arus yang akan mendeteksi tegangan dan arus dari sistem distribusi tiga fasa, yaitu fasa $\mathrm{R}, \mathrm{S}$ dan $\mathrm{T}$ yang kemudian data tersebut akan dikirimkan ke mikrokontroller Arduino Mega (Efrizal. F, 2016)

. Setelah dari Arduino Mega data fasa R, S dan $\mathrm{T}$ akan ditampilkan pada LCD sebagai output di lokasi alat, ketika terjadi low voltage, high voltage atau short circuit maka buzzer akan berbunyi sebagai alarm notifikasi.

Kemudian data-data tersebut akan di gabungkan oleh Arduino Mega untuk di kirimkan menuju Wemos D1 Mini, sehingga data yang terdapat di Wemos D1 Mini akan di parsing untuk mengetahui tegangan dan arus pada setiap fasa R, S dan T. Aplikasi Blynk akan memberikan notifikasi ketika ada sesuatu yang tidak normal dari ke tiga fasa dan ketika Wemos D1 Mini tidak mengirimkan data maka akan ada notifikasi pula apakah Wemos D1 Mini tidak terkoneksi atau ada masalah pada sistem distribusi atau fasa R, S, T n

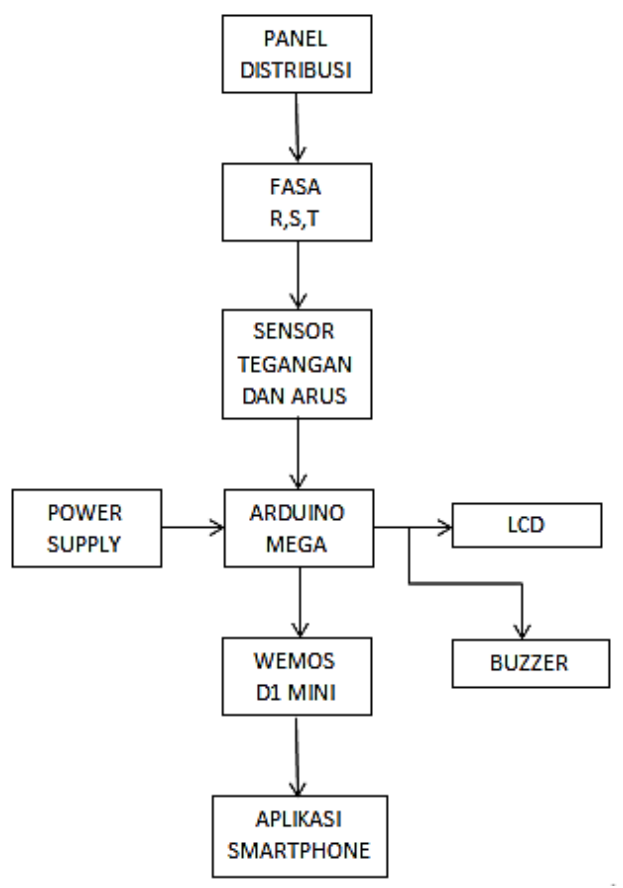

Gambar 1. Diagram Blok Perancangan

\section{Tahapan Perancangan}

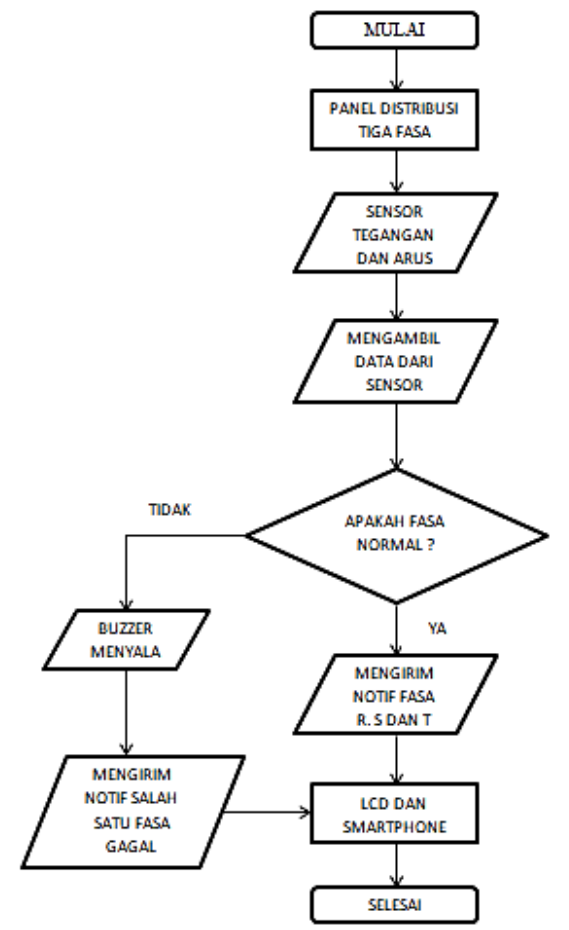

Gambar 2. Flowchart Monitoring 3 Fasa 
Berikut wiring perancangan alat pada $\begin{aligned} & \text { komponen power supply dan } \\ & \text { mikreokontroller. }\end{aligned}$

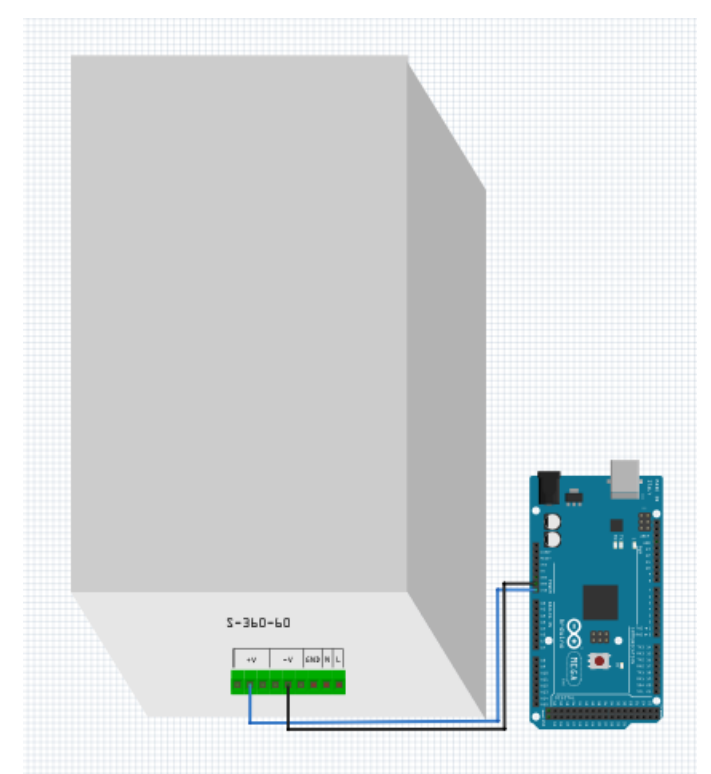

\section{Gambar 3. Wiring Arduino Dan Power} Supply

Berikut wiring perancangan alat pada komponen mikrokontroller dan sensor arus dan tegangan.

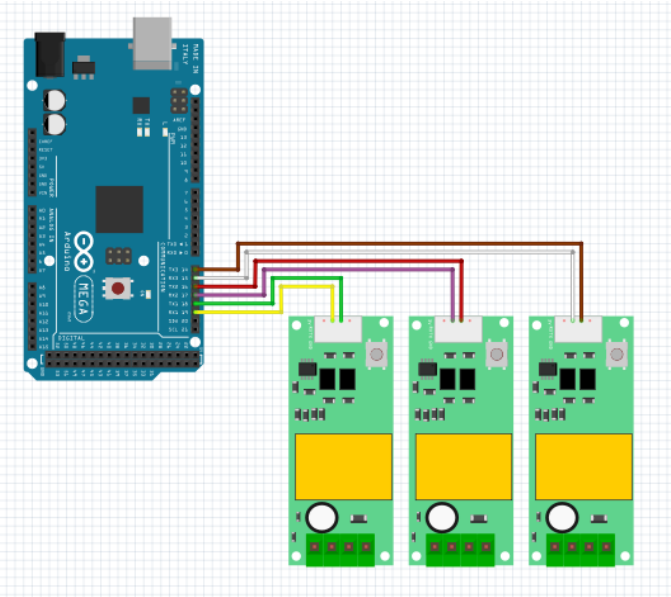

Gambar 4. Wiring PZEM-004T

Berikut wiring perancangan alat pada komponen mikrokontroller dan Wemos D1 Mini.

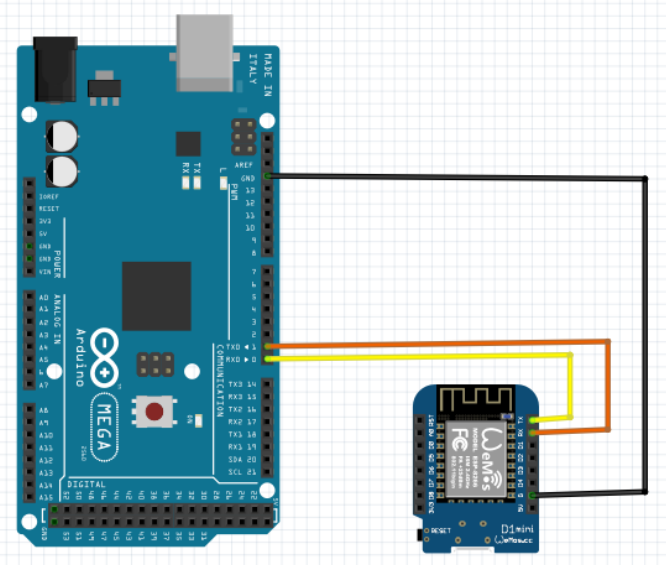

Gambar 5. Wiring Wemos D1 Mini

Berikut wiring perancangan alat pada komponen mikrokontroller dan LCD.

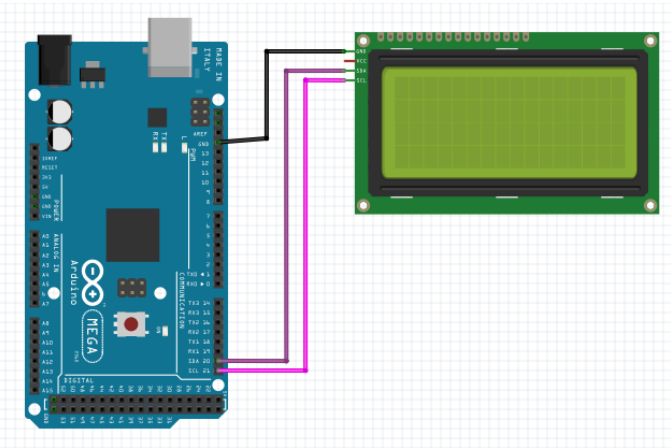

Gambar 6. Rangkaian LCD

Berikut wiring perancangan alat pada komponen mikrokontroller dan Buzzer.

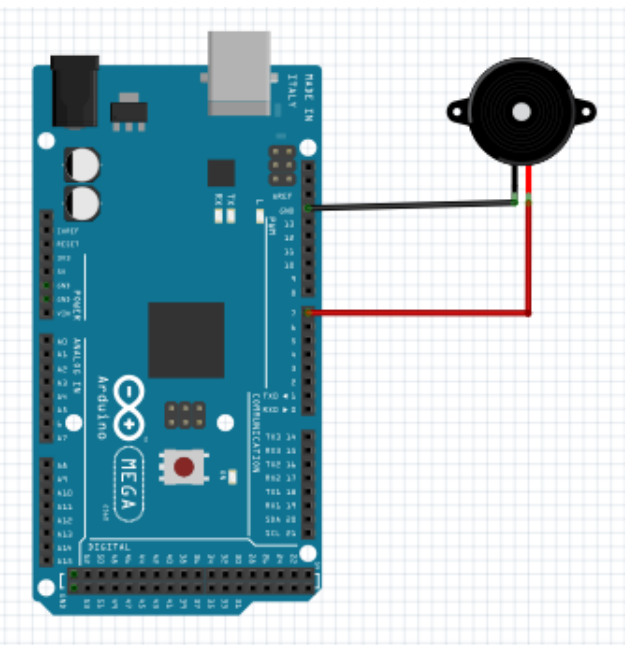

Gambar 7. Rangkaian Buzzer 
Setelah melakukan tahap installasi aplikasi Arduino IDE pada laptop maka langkah selanjutnya melakukan pemgrograman coding arduino untuk menjalankan sistem rancangan sesuai dengan tujuan yang diinginkan.

Kemudian melalukan instalasi pada Blynk lalu melakukan registrasi atau sign up akun baru. Registrasi cukup hanya dengan mendaftarkan alamat email dan mengisi kolom password, kemudian pengguna akan di arahkan untuk membuat project baru. Aplikasi Blynk dengan akun yang sama dapat digunakan di beberapa perangkat smartphone. Dengan syarat adanya akses internet dan login dengan email dan password yang telah ditentukan. Wemos D1 Mini pada alat monitoring pun harus terhubung dengan Wifi yang telah dicantumkan pada coding arduino.

\section{Uji Coba Rancangan}

Pengujian alat ini bertujuan untuk mengetahui cara kerja perangkat dan menganalisa tingkat realibilitas, kelemahan serta keterbatasan spesifikasi fungsi dari aplikasi yang telah dibuat. Selain itu pengujian ini juga bertujuan untuk mengetahui tentang bagaimana kondisi sistem ini agar aplikasi ini dapat dipakai dengan secara optimal.

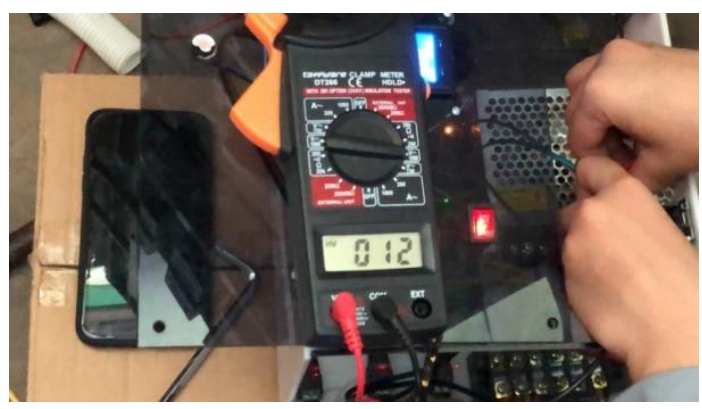

Gambar 8. Pengukuran Power Supply

\begin{tabular}{|c|c|c|}
\hline $\begin{array}{c}\text { Tegangan } \\
\text { Input }\end{array}$ & $\begin{array}{c}\text { Tegangan } \\
\text { output yang } \\
\text { diinginkan }\end{array}$ & $\begin{array}{c}\text { Tegangan } \\
\text { Output }\end{array}$ \\
\hline R 239 VAC & 12 VDC & \\
\cline { 1 - 1 } S 240 VAC & 12 VDC & \multirow{2}{*}{12 VDC } \\
\cline { 1 - 1 } T 239 VAC & 12 VDC & \\
\hline
\end{tabular}

Selanjutnya melakukan pengujian pada power supply, maka langkah selanjutnya adalah pengujian Arduino.

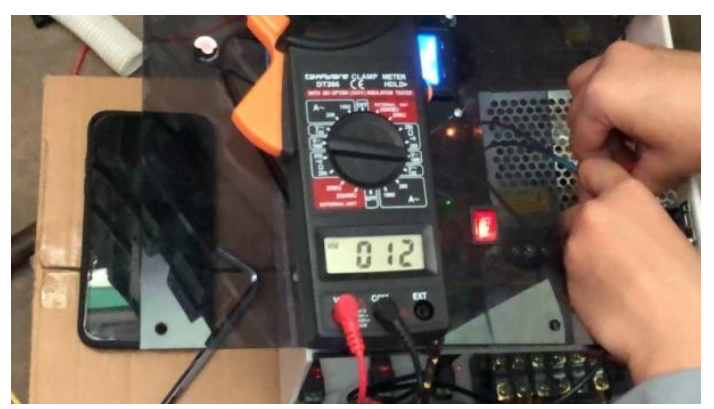

Gambar 9. Pengukuran Arduino Mega

Tahap berikutnya adalah melakukan pengujian pada sensor tegangan dan arus.

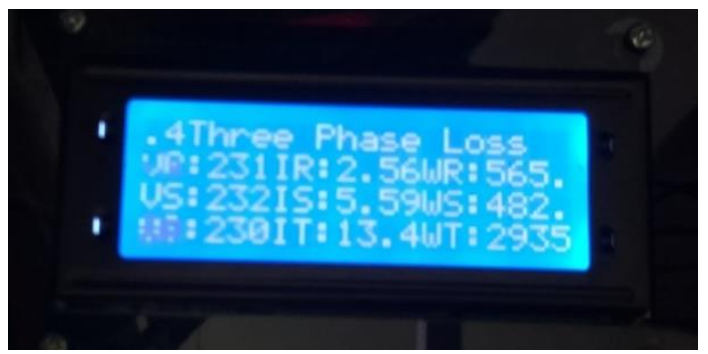

Gambar 10. Sensor Tegangan dan Arus Pada LCD

Tabel 1. Hasil Pengujian Power Supply 
Airman: Jurnal Teknik dan Keselamatan Transportasi

Volume 4 Nomor 2 Desember 2021

P-ISSN 2622-0105 | E-ISSN 2716-1196

Tabel 2. Hasil Pengujian Sensor Tegangan

\begin{tabular}{|c|c|}
\hline $\begin{array}{c}\text { Hasil Pengukuran } \\
\text { Dengan Avometer }\end{array}$ & $\begin{array}{r}\text { Hasil Pembacaan } \\
\text { Sensor Tegangan }\end{array}$ \\
\hline $\mathrm{R}=239 \mathrm{~V}$ & $\mathrm{R}=231 \mathrm{~V}$ \\
\hline $\mathrm{S}=240 \mathrm{~V}$ & $\mathrm{~S}=232 \mathrm{~V}$ \\
\hline $\mathrm{T}=239 \mathrm{~V}$ & $\mathrm{~T}=230 \mathrm{~V}$ \\
\hline
\end{tabular}

Tabel 3. Hasil Pengujian Sensor Arus

\begin{tabular}{|c|c|}
\hline $\begin{array}{c}\text { Hasil Pengukuran } \\
\text { Tang Ampere }\end{array}$ & $\begin{array}{c}\text { Hasil Pembacaan } \\
\text { Sensor Arus }\end{array}$ \\
\hline $\mathrm{R}=2,00 \mathrm{~A}$ & $\mathrm{R}=2,53 \mathrm{~A}$ \\
\hline $\mathrm{S}=5,29 \mathrm{~A}$ & $\mathrm{~S}=5,57 \mathrm{~A}$ \\
\hline $\mathrm{T}=2,67 \mathrm{~A}$ & $\mathrm{~T}=2,97 \mathrm{~A}$ \\
\hline
\end{tabular}

Selanjutnya adalah proses compiling Arduino mega pada aplikasi arduino IDE.

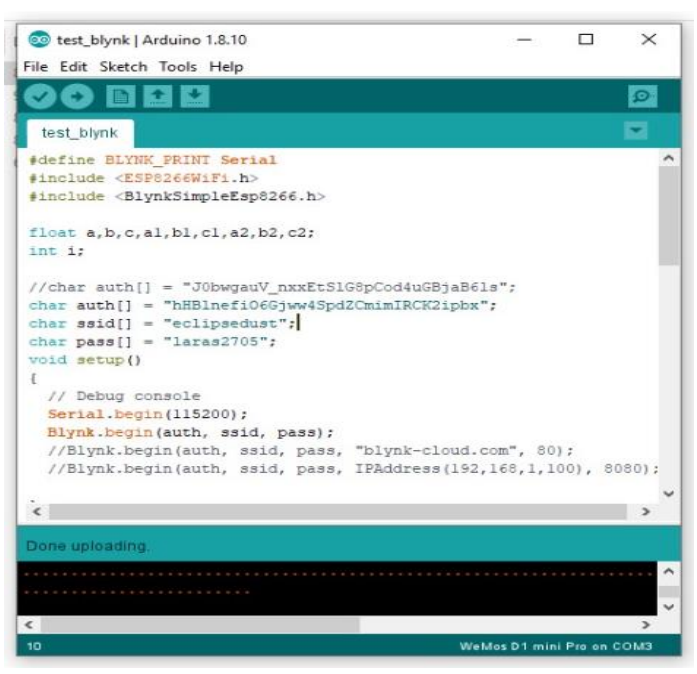

Gambar 11. Compiling Arduino
Untuk melakukan pengujian perangkat lunak pada smartphone. Berikut adalah hasil tampilan pada aplikasi Blynk yang digunakan sebagai media notifikasi apabila terjadi gangguan pada sistem distribusi dan monitoring daya.

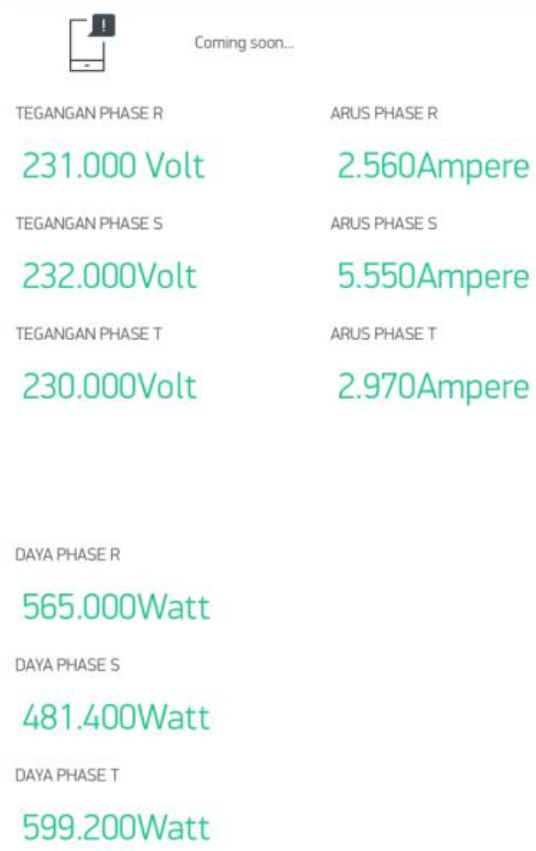

Gambar 12. Data Pada Aplikasi Blynk

Kemudian lakukan uji coba alat dengan simulasi kegagalan fasa atau hilangnya salah satu fasa.

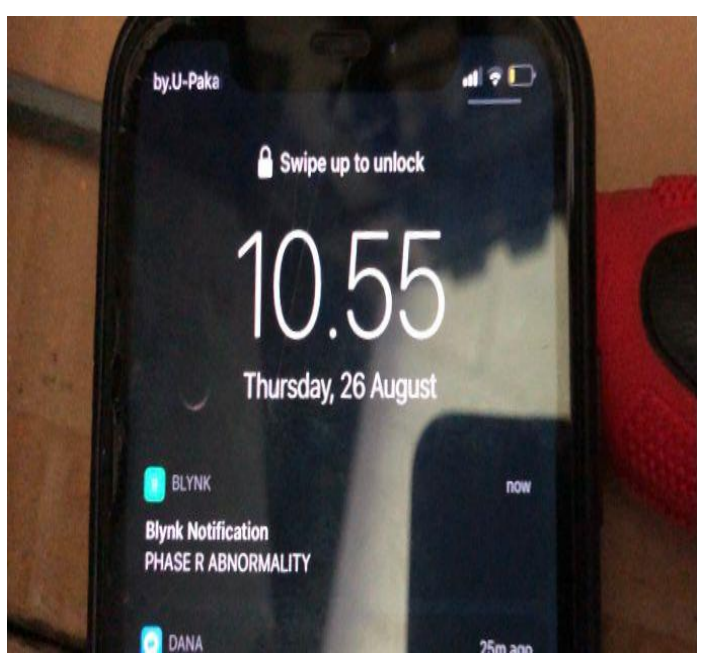

Gambar 13. Notifikasi Pada Smartphone 


\section{[G] Kontrol 3 Phase Los: $\square$

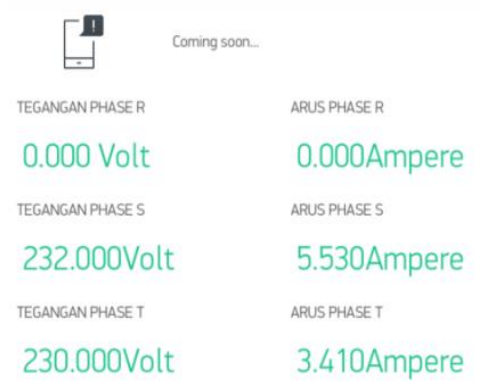 \\ DAYAPHASER \\ 0.000Watt \\ DAYAPHASES \\ 481.500Watt \\ DARAPHASET \\ 710.500 Watt \\ Gambar 14. Tampilan Blynk Ketika Hilangnya Salah Satu Fasa}

Kondisi diatas adalah kondisi saat fasa $\mathrm{R}$ tidak ada tegangan sehingga indicator berubah menajdi 0 dan buzzer pada alat berbunyi yang menjadikan indicator adanya kegagalan pada salah satu fasa yang diambil contoh pada fasa $\mathrm{R}$ tersebut sehingga sensor tegangan dan arus tidak mendeteksi yang membuat pendekteksi pada fasa tersebut bekerja.

Apabila tegangan sudah kembali normal nilai 0 akan berubah kembali ada nilainya dan buzzer pada alat berhenti yang menandakan tegangan kembali normal pada system tiga fasa R, S dan T tersebut (Nasution A., Putra R., Madona E., 2014).

\section{Interpretasi Hasil Pengujian}

Dari hasil pengujian alat secara keseluruhan, rancangan alat ini telah memenuhi tujuan yang diharapkan. Alat monitoring fasa dan daya yang menggunakan Arduino Mega, Wemos D1 Mini dan sensor PZEM-004T dapat digunakan sesuai fungsinya masing-masing (Fatoni N. H., Sabar S., Moh M., 2017). Pengujian alat menunjukkan bahwa perangkat keras dan perangkat lunak telah terhubung dengan benar. Pada saat adanya salah satu fasa yang hilang maka buzzer akan berbunyi dan notifikasi akan dikirimkan ke aplikasi Blynk melalui internet. Teknisi dapat melihat data real time pada LCD maupun pada aplikasi blynk.

Alat ini dapat mendeteksi dari jarak jauh sistem distribusi tiga fasa dengan sensor tegangan dan arus PZEM-004T memakai serial sehingga membutuhkan waktu 5 detik untuk memastikan serial pada sensor arus dan tegangan PZEM-004T sudah dibaca lalu dikirimkan ke Wemos D1 Mini dan juga melalui serial sehingga terdapat delay pengiriman data antara Arduino Mega dengan Wemos D1 Mini untuk kemudian dikirimkan ke Blynk.

\section{Diskusi}

Hasil pengujian rancangan yang dilakukan dinyatakan sesuai dengan kondisi yang diinginkan, namun perlu diperhatikan kembali mengenai rangkaian pada 3 fasa yang dilakukan teknisi dan koneksi internet pada alat dan aplikasi.

\section{KESIMPULAN}

1. Dari hasil pengujian dan terpasangnya alat sensor arus dan tegangan di setiap fasa maka nilai besaran tegangan $(\mathrm{V})$, arus (I) dan daya (P) dapat dimonitoring secara jarak jauh dari aplikasi Blynk pada smartphone.

2. Rancang bangun alat ini juga bisa mendeteksi gangguan fasa supaya teknisi dapat segera menganalisa serta memperbaikinya.

\section{Saran}


1. Penulis menyarankan untuk membuat notifikasi atau alarm ketika perangkat tidak terhubung pada internet atau adanya error di LCD dan Aplikasi Blynk.

2. Sebaiknya diperlukan tambahan alat proteksi pada alat.

3. Perlu untuk menambahkan UPS (Uninterruptible Power Supply) sebagai catu daya cadangan dan menambahkan sambungan pada power supply, supaya ketika fasa $\mathrm{S}$ mati maka akan bisa terdeteksi semua fasa.

\section{DAFTAR PUSTAKA}

Amaro N. (2017) Sistem Monitoring Besaran Listrik dengan Teknologi IoT, dari Fakultas Teknik Universitas Lampung.

Badaruddin M., (2012) Alat Deteksi Kehilangan Salah Satu Fasa Pada Sistem Tiga Fasa, Dari Fakultas Teknik Universitas Mercu Buana.

DaffaRosydi, A., Prasetyono, E., \& Windarko, N. A. (2019). Prototipe Pendeteksi Titik Gangguan pada Jaringan $20 \mathrm{kV}$ dengan Metode Arus Gangguan. Techné: Jurnal Ilmiah

Elektroteknika, 18(02), 127135.

Efrizal. F (2016) Jurnal Rancang Bangun Alat Monitoring Arus dan Tegangan Berbasis Mikrokontroler oleh Afrizal Fitriand

Fatoni N. H., Sabar S., Moh M. (2017) Jurnal Alat Monitoring Pemakaian Energi Listrik Berbasis
Android Menggunakan Modul PZEM-004T, Jurusan Teknik Elektro Politeknik Negeri Malang

Iyan A. (2019) Pengukur Daya Listrik Menggunakan Sensor Arus Acs712-05a Dan Sensor Tegangan Zmpt101b, Dari Jurusan Teknik Universitas Negeri Yogyakarta.

Nasution A., Putra R., Madona E., (2014) Rancang Bangun Alat Monitoring Daya 3Phase Berbasiskan Mikrokontroller Yang Dapat Dibaca Secara Online Pada Laboratorium Mikroprosesor Politeknik Negeri Padang, Seminar Nasional Ilmu Komputer (SNIK 2014). 